\title{
Buddhist votive stele with carved Buddhist figures and inscriptions
}

Kate Lingley

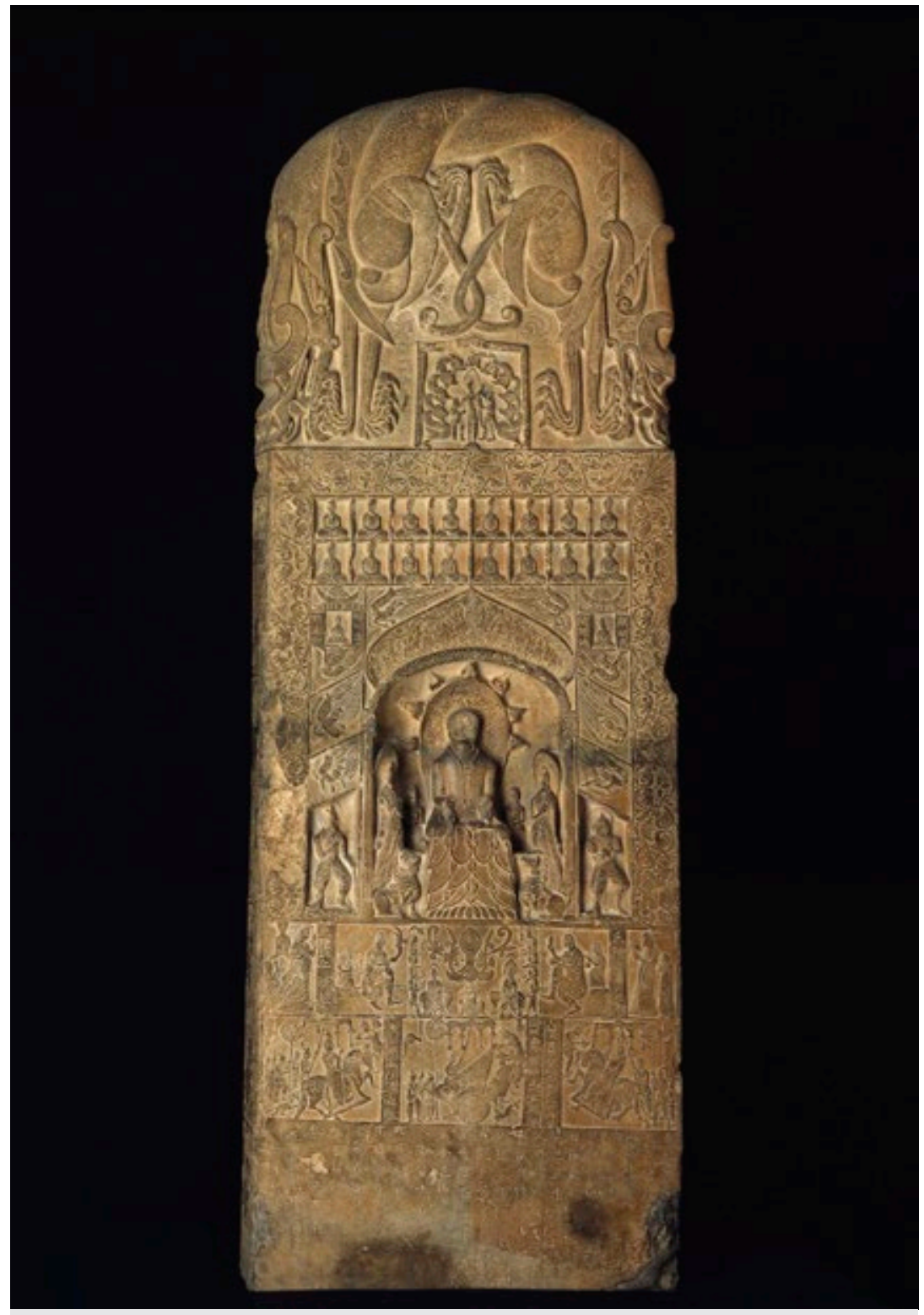

Buddhist votive stele with carved Buddhist figures and inscriptions, Northern Wei dynasty, 529 A.D.

This is a Buddhist votive stele made in the sixth century in north central China. It probably stood either in the courtyard of a Buddhist monastery, or in a public place such as a market square or at a major crossroads. It is iconographically complex: the two dragons at the top are decorative and conventional (more or less), but they enclose an image of the infant Buddha being bathed by nagas just after his birth. Working downward from the viewer's perspective, the stele introduces a vinescroll border almost 
certainly adapted from Silk Road textiles; two rows of unnamed Buddhas, probably as a reference to the multiplicity of Buddhas described in many Chinese Mahayana sutras; a principal niche with a main Buddha icon, in this period probably Sakyamuni, surrounded by attendants, lions, guardians, and worshipping figures; then two rows of donor figures; and at the very bottom, an inscription about the circumstances of the stele's dedication in year 529 by a Buddhist charitable society made up of laymen, laywomen, and monastics.

The charitable society's primary function was to allow people of ordinary means to pool their resources to sponsor various religious activities, including the making of Buddhist images and monuments, offerings to the Buddha (food, flowers, music, etc.), public sutra lectures by an eminent monk, the printing and distribution of Buddhist texts, vegetarian feasts for the poor, and so on. They might also make contributions to the support of a monk/nun or a monastery. Although their main purpose was Buddhist merit-making, the bylaws of such organizations reveal that they could also function as mutual aid societies, since their members had established obligations toward each other if one of their number was widowed, ill, or fell on hard times.

The members of this charitable organization take their places as donor figures on the front of the monument. There are rows of smaller donor figures on the sides and back of the stele as well, each inscribed with a name. The figures visible on the front are the leaders and principal donors of the society. They either served as officers of the society, or gave extra money to "sponsor" a particular Buddha figure or a particular part of the ceremony of dedication. The figures on the sides and back of the stele include such principal donors, but mostly represent ordinary donors-members of the society who contributed to the project, but who had no special office or role in the association.

Thus in the upper register of donors, at far left, appears the preceptor Bhiksu Fazang, a monk. He was one of the monastic advisors of the society-probably consulted by lay members on questions of doctrine. To his right is a symmetrical group of worshippers surrounding a large incense burner at the center, supported by a powerful crouching figure. There are paired bodhisattvas on elephant-back, then two vertical stacks of acrobats sitting on each others' shoulders and extending their hands with offerings (acrobatic performances were often part of Buddhist festivals at this time); then a pair of seated monks. There is a second preceptor to the right, completing the symmetry.

The lower register contains three little scenes, each representing one of the "major donors" of the monument. At far left is Lin Yansheng, who sponsored the main Buddha icon on the monument. He's shown on horseback with a whole entourage of servants and attendants with fans and canopies, a testament to his social status. The middle scene is inscribed with the name of Lin Sengming, who sponsored the "eye-opening" ceremony, when the Buddha's eyes were dotted in, "enlivening" the figure; but the inscription says that he acted in honor of his daughter Lin Jingsheng, and the image shows a lady's closed oxcart, with servants. The third figure, at far right, shows another man on horseback with servants, and the inscription reveals yet another Lin, who sponsored the vegetarian feast associated with the dedication, in honor of his deceased 
elder brother.

These major donors were almost certainly members of the same extended family; this was not unusual for the time. Such Buddhist societies were frequently organized by people who already had some other connection, being members of the same lineage, village, or monastery. Other surnames found among the donors of this stele include Guan, Wen, Qi, and Yang, perhaps representing in-laws of the Lin family, or other families from the same village.

(C) Kate Lingley

\section{Citation Guide}

1. Kate Lingley, "Buddhist votive stele with carved Buddhist figures and inscriptions," Object Narrative, in Conversations: An Online Journal of the Center for the Study of Material and Visual Cultures of Religion (2014), doi:10.22332/con.obj.2014.18

Lingley, Kate. "Buddhist votive stele with carved Buddhist figures and inscriptions." Object Narrative. In Conversations: An Online Journal of the Center for the Study of Material and Visual Cultures of Religion (2014). doi:10.22332/con.obj.2014.18

\section{Yale}

Copyright 2016 Yale University All rights reserved. 